\title{
Effect of leaf litter mulch on germination and initial seedling growth of some traditional field crops in Garhwal Himalaya, India
}

Bhupendra Singh, C. S. Dhanai and Padam Singh

Received : 27.12.2017; Revised : 03.03.2018; Accepted : 15.03.2018

See end of the Paper for authors' affiliation

Correspondence to :

Bhupendra Singh

Department of Forestry and Natural Resource Management, H.N.B. Garhwal University,

Srinagar, Garhwal

(Uttarakhand) India Email : butola_bs@yahoo.co.in
-ABSTRACT : The present investigation was carried out to investigate the effect of litter mulch on germination and growth of some field crops of Garhwal Himalaya region, India. Leaf litter was collected from the under story of trees crops i.e. Grewia oppositifolia, Ficus roxburghii, Celtis australis and Boehmeria rugulosa and dry in sun for further experiments. The experiments were conducted in pot culture. The results of present study reveal that leaf litter mulch of G. oppositifolia significantly inhibited the germination and of E. coracana and $P$. mungo summer crops and $F$. roxburghii was significantly inhibited the germination of $H$. vulgare winter crops. Leaves litter of $G$. oppositifolia $C$. australis reduced the radicle and plumule growth of $G$. max, respectively. Similarly, biomass of summer field crops of G. max and E. coracana significantly inhibited by the G. oppositifolia leaves litter. While, winter field crop H. vulgare was significantly inhibited by leaves litter of G. oppositifolia.

- KEY WORDS : Agriculture crops, Germination, Leaf litter mulch, Seedling growth, Tree crops

-HOW TO CITE THIS PAPER : Singh, Bhupendra, Dhanai, C.S. and Singh, Padam (2018). Effect of leaf litter mulch on germination and initial seedling growth of some traditional field crops in Garhwal Himalaya, India . Internat. J. Agric. Engg., 11(1) : 199-204, DOI: 10.15740/HAS/IJAE/11.1/ 199-204. 